\title{
Bio-fabrication of silver nanoparticles using naturally available wild herbaceous plant and its antibacterial activity
}

\author{
Seyed Saeid Mohammadia, Nahid Ghasemia,*, Majid Ramezania \\ a Department of Chemistry, Arak Branch, Islamic Azad University, Arak, Iran
}

Received: 13 October 2019, Accepted: 02 November 2019, Published: 23 November 2019

\begin{abstract}
The irrational use of antibiotics has caused an increment in bacterial resistance to these compounds, leading humans to go in quest of alternative effective antimicrobial factors with less side effects as compared to antimicrobial compounds with less unwanted side effects. Silver Nanoparticles (AgNPs) could be considered as one of the most important antibacterial agents. In this study, the aqueous extract of Fumaria officinalis leaf was prepared and used in optimal conditions $(\mathrm{pH}=10$, extract volume $=8$, metal salt concentration $=10 \mathrm{mM}$, temperature $100{ }^{\circ} \mathrm{C}$ and time $=120 \mathrm{~min}$ ) for reduction of silver ions and synthesis of AgNPs. The resulted AgNPs were characterized by different techniques including UV-Vis, and XRD, FESEM, TEM, EDX and FTIR, respectively. Finally, the antibacterial activity of AgNPs on two pathogens (Escherichia coli (PTTC 1707), and Staphylococcus aureus (PTTC 1112)), was investigated using agar disk diffusion and minimum inhibitory concentration (MIC) test. The extract of Fumaria officinalis displayed high potential to synthesize stable spherical AgNPs in shape with size below $25 \mathrm{~nm}$. The nanoparticles showed considerable antibacterial effect on two tested bacteria. The minimum inhibitory concentration on Escherichia coli and Staphylococcus aureus for AgNPs was 12.5 and $6.25 \mu \mathrm{g} / \mathrm{mL}$, respectively.
\end{abstract}

Keywords: Fumaria Officinalis; XRD; TEM; silver nanoparticles; antibacterial.

\section{Introduction}

One of the applications of nanobiotechnology has to do with the use of metal nanoparticles as a novel technique in microbial infections treatment. Metal nanoparticles can be yielded through various chemical and physical methods. Chemical synthesis usually includes ion salts reduction at an appropriate ambient utilizing reduction agents like sodium citrate. As nanoparticles have high reaction ability and agglomeration tendency, to keep their desired properties, a stabilizer (capping agent) adds to them. Using stabilizers is a costeffective technique, however; chemical species absorbed on particle surface may cause inappropriate environmental and echo effects and be hazardous to health. Physical methods, including

Eurasian Chem. Commun., (2020) 87-102

Corresponding author: Nahid Ghasemi

Tel: +98 (86) 34135421, Fax: +98 (86) 34135421

E-mail:n-ghasemi@iau-arak.ac.ir 
evaporation-condensation and lasererosion have also disadvantages such as dependability to expensive equipment, high energy consumption, and low yield [1-6]. On the other hand, widespread applications of metal nanoparticles caused researchers utilize simple, cheap, and non-toxic synthesis methods. Green synthesis of nanoparticles is a new research focus among sundry techniques of synthesizing nanoparticles. The method is gaining acceptance due to its eco-friendly nature. It is a bottom-up approach method; the synthesis route includes use of microorganisms (yeast, bacteria, algae, fungi and viruses), plants or plant extracts [7-9]. Therefore, it is suggested to use green synthesis as echocompatible alternative methods instead of chemical and physicalones for nanoparticles biosynthesis[10,11]. Until now, biosynthesis of metal nanoparticles using different types of bacteria, yeasts, algae, plants, and plant extracts are reported [12-15]. Synthesis of metal nanoparticles using plant extracts is superior to other biological processes due to plants' frequency, availability, cost-effectiveness, and not requiring cell cultures maintenance. Plant extracts are considered as suitable options for largescale green synthesis of metal nanoparticles [16]. Some researches have confirmed the role of polyphenols, carbohydrates, proteins, terpenoids, and generally, plant organic compounds in the reduction of metal salts during the process of nanoparticles synthesis [17,18]. Among nanoparticles, gold and AgNPs (AgNPs) have gained more attention because of their environmental potent as well as medical applications[19].

The advent of nanotechnology as well as antimicrobial properties of silver and its highly potent in nano scales has made possible the use of silver in overcoming different human and animal pathogens.
AgNPs are known as growth-inhibitory compounds with anti-inflammatory and anti-bacterial properties which can be effective in faster healing of wounds [20].

Various plants are utilized for the synthesis of gold and silver, which include Parkia Speciose, Pelargonium endlicherianum, Fraxinus excelsior, Embelia ribes. Nat Prod Res, Zingiberofficinale and Galaxaura elongata [21-26]. Studies have shown that nanoparticles yielded through plant extracts are capped by plant metabolites as well as carbohydrates and proteins, bringing about more stability and biocompatibility of the particles as well as less environmental challenges [27]. As medicinal plants are certainly proved as good candidates for metal nanoparticles synthesis due to their antioxidant properties, this study explored AgNPs synthesis using Fumaria officinalis extract through a bio-compatible method (Figure 1). There are 7 herbaceous oneyear species of the Fumariaceae family known in Iran. The medicinal species of this plant in the world is called Fumaria officinalis L. (Figure 1) which has cholagogue property. Alkaloids within this herb helps to both increasing and decreasing bile flow. The fumaric acid within this herb brings about diuretic and laxative properties in folk medicine and removes skin diseases [28]. It is an enhancing herbal which acts as a blood purifier and appetite stimulant. The medicinal section of this herb consists of aerial organs. It has very tiny purple flowers with hand-shaped green leaves, bitter taste, and no smell. Alkaloids are the most effective ingredients within this plant [29], which include fumarine, protopine, cryptocoine, scoulerine, tetrahydro-coptisin, and other minor alkaloids. Other efficient compounds within this plant are potassium salts, fumaric acid, flavonoids, fumaramine, 
fumaramidine, fumariflorine, bicuculline. In the present study, efficient parameters in AgNPs biosynthesis using Fumaria officinalis aqueous extract were characterized and the effect of synthesized AgNPs on two pathogens (Staphylococcus aureus and Escherichia coli) as well as their inhibitory condensation were examined.

\section{Experimental}

\section{Chemical}

Chemical materials under investigation with high purity were obtained. $\mathrm{AgNO}_{3}$, $\mathrm{HCl}$, and $\mathrm{NaOH}$ were purchased from Merck Company (Germany) and microorganisms, including Staphylococcus aureus and Escherichia coli were obtained from Iranian Research Organization for Science and Technology (IROST). Moreover, double-distilled water was used to wash and prepare the solution.

\section{Preparation of fumaria officinalis} extract

First, $100 \mathrm{~g}$ of fresh leaves of Fumaria officinalis (Figure 1) was sterilized with sodium hypochlorite 5\% (obtained from Merck Co, Germany) for $5 \mathrm{~min}$ and washed by distilled water 3 times. Then, the solution was sterilized with alcohol $70 \%$ (obtained from Merck Co, Germany) for $2 \mathrm{~min}$. Finally, it was washed with distilled water 3 times and let dry at room temperature.

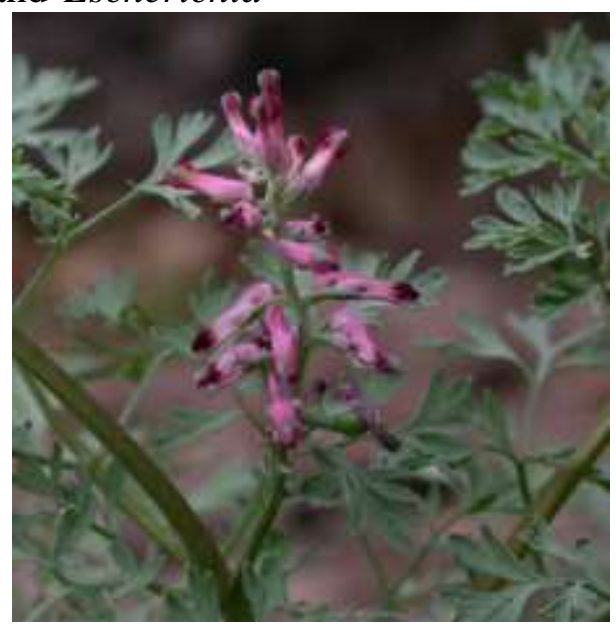

Figure 1. Fumaria officinalis plant

To prepare aqueous extract, $20 \mathrm{~g}$ of the extract was poured into a beaker 250 $\mathrm{mL}$ and $200 \mathrm{~mL}$ double-distilled water was added to it. This compound was put into a shaker incubator at $95{ }^{\circ} \mathrm{C}$ for 30 min. Then, the yielded aqueous extract was filtered by whatman filter paper (grade $42-\mathrm{UK}$, with pore size $20 \mu$ ). After that, the sample was placed in the centrifuge (Superspeed Sorvall B-RC2) at the speed of $9000 \mathrm{rpm}$ for $10 \mathrm{~min}$ [30]. Finally, the aqueous extract was put in the refrigerator at $4{ }^{\circ} \mathrm{C}$.

Biosynthesis of AgNPs using Fumaria officinalis extract
First, $\mathrm{AgNO}_{3}$ solution $1 \mathrm{mM}$ was prepared. $95 \mathrm{~mL} \mathrm{AgNO}_{3} 1 \mathrm{mM}$ was added to $5 \mathrm{~mL}$ extract within a $250 \mathrm{~mL}$ erlenmeyer at constant temperature 25 ${ }^{\circ} \mathrm{C}$ and pH 5.6. Then, the sample was put into a shaker incubator at the rate of $150 \mathrm{rpm}$ for $30 \mathrm{~min}$. The color of the solution changed to dark brown as nanoparticles were formed, indicating that AgNPs were synthesized (Figure 2 a, b). After an appropriate time, to confirm silver ions $\left(\mathrm{Ag}^{1+}\right)$ reduction as well as AgNPs synthesis $\left(\mathrm{Ag}^{0}\right), 0.2 \mathrm{~mL}$ of the colloidal sample was mixed with $2 \mathrm{~mL}$ sterilized distilled water and its optical properties were analyzed by UV-Vis 
spectrophotometer (Jasco V650, Japan) at wavelengths of $300-800 \mathrm{~nm}$. Then, parameters affecting AgNPs synthesis including $\mathrm{pH}$, extract volume, $\mathrm{AgNO}_{3}$ concentration, temperature and reaction

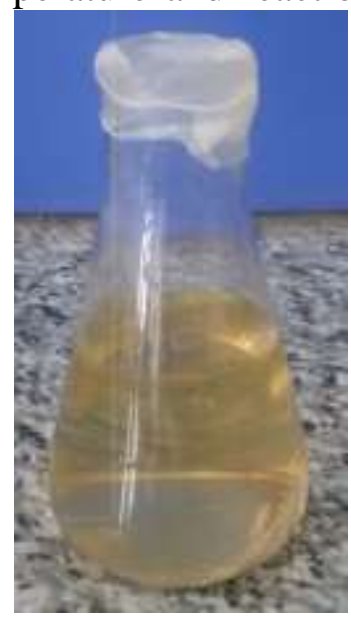

A time were examined with the aim of obtaining nanoparticles with more homogeneous morphology and smaller sizes.

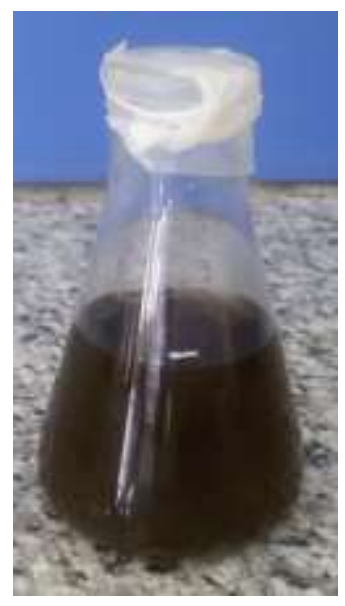

$\mathrm{B}$

Figure 2. a) Fumaria officinalis leaf extract solution, b) Colour of the Fumaria officinalis extract solution after reaction with $\mathrm{AgNO}_{3}$.

Optimization of parameters affecting on nanoparticles synthesis

Effect of $\mathrm{pH}$ on silver nanoparticle synthesis

To optimize $\mathrm{pH}$ of the reaction, $\mathrm{pH}$ of the 5 erlenmeyers containing $5 \mathrm{~mL}$ extract and $95 \mathrm{~mL} \mathrm{AgNO}_{3}$ solution $1 \mathrm{mM}$ was set at 2, 4, 6, 8, and 10. In the next step, the samples placed at $25{ }^{\circ} \mathrm{C}$ for $30 \mathrm{~min}$ and were submitted to a UV-Vis analysis with the absorbance at regions 300-800 $\mathrm{nm}$, and the optimal $\mathrm{pH}$ was determined (Figure 3). To set the solutions' $\mathrm{pH}$, either of the solutions, sodium hydroxide or $\mathrm{HCl}$ with concentration of $0.1 \mathrm{M}$ was utilized.

Effect of extract volume on silver nanoparticle synthesis

To optimize the extract volume, 2, 4, 6, and $8 \mathrm{~mL}$ of the extract were added to 95 $\mathrm{mL} \mathrm{AgNO}_{3}$ solution $1 \mathrm{mM}$, and the related $\mathrm{pH}$ was determined. The extract was used as a reductant and stabilizing agent. Then, the samples placed at $25^{\circ} \mathrm{C}$ for $30 \mathrm{~min}$ and were submitted to a scanning UV-Vis analysis (Figure 4) and the final optimized extract volume was yielded.

Effect of metal salt concentration on silver nanoparticle synthesis

To find an optimal concentration for $\mathrm{AgNO}_{3}$ solution, the optimized extract volume was added to $95 \mathrm{~mL} \mathrm{AgNO}_{3}$ solution with various concentrations 1,3 , 5 , and $10 \mathrm{mM}$, and optimal $\mathrm{pH}$ of the reaction was set. Finally, the samples placed at $25{ }^{\circ} \mathrm{C}$ for $30 \mathrm{~min}$ and were submitted to a UV-Vis analysis and the optimal concentration was obtained (Figure 5).

Effect of temperature on silver nanoparticle synthesis

The synthesis of nanoparticles using the mentioned extract is feasible at any temperature (even at room temperature). However, to obtain nanoparticles with more desired size and morphology, the reaction temperature is required to be optimized. To this end, solutions under previously-mentioned optimal conditions were exposed to $25,45,65$, 80 , and $100^{\circ} \mathrm{C}$ separately. Then, the final 
samples were submitted to a UV-Vis analysis and its absorbance peaks were obtained (Figure 6).

\section{Effect of time on silver nanoparticle synthesis}

To reach the best conversion rate in AgNPs synthesis under abovementioned reaction, several solutions were examined under different reaction time spans (from the moment of mixing extract with $\mathrm{AgNO}_{3}$ solution until 120 min after the synthesis). In the last step, the samples were submitted to a UV-Vis analysis and its absorbance peaks were obtained (Figure 7).

Characterization of AgNPs synthesized by Fumaria officinalis

To confirm the results of UV-Vis analysis, the size and morphology of the synthesized AgNPs were analyzed through X-Ray Diffraction (XRD, X'Pert Pro PANalytical X-ray Diffractometer, Netherland) and Field Emission Scanning Electron Microscopy (FESEM,

KYKY-EM3200)

Transmission Electron Microscopy (TEM , Technai T20, Philips), Energydispersive X-ray spectroscopy (EDX, VEGA TESCAN SEM). The natures of reduction biomolecules as well as the effect of stabilizing agents were analyzed by Fourier Transform Infrared Spectroscopy (FTTIR, Perkin Elmer, Spectrum RX1).

\section{Antibacterial Test \\ Preparing culture medium}

First, $20 \mathrm{~g}$ of the nutrient agar was poured into $1000 \mathrm{~mL}$ distilled water and boiled until it was solved and the solution color became transparent. Then, the solution was placed within the autoclave at $121^{\circ} \mathrm{C}$. In the next stage, the culture medium was applied to the sterile plates, allowed to cool, and got ready for carrying out the bacterial test.

Agar disc diffusion Test
The present study investigated the antibacterial effect of AgNPs on the growth and activity of Staphylococcus aureus (ATCC: 25923) and Escherichia coli (ATCC:25923). The bacteria strains were obtained from Iranian Research Organization for Science and Technology and prepared according to the instructions of the mentioned organization. The bacteria in question were cultured in nutrient broth and the microorganisms were cultured on the plate using Mueller-Hinton Agar. First, various volumes of bacterial suspensions with a 0.5 McFarland standard were swabbed and mass cultured across 3 directions. The Sterile paper $(6 \mathrm{~mm}$ diameter) impregnated with Fumaria officinalis extract, AgNPs synthesized, double-distilled water (as negative control) and $\mathrm{AgNO}_{3}$ (as positive control) were placed on the surface each plate and left at $37{ }^{\circ} \mathrm{C}$ for $24 \mathrm{~h}$. Each test was replicated three times, finally, the diameter of the growth inhibition zone was measured using caliper, and mean size of zones were calculated [31].

\section{Examining minimum inhibitory concentration}

First, 0.21 gr of Mueller Hinton Broth medium powder was poured and solved into $20 \mathrm{~mL}$ distilled water and put into autoclave for $1 \mathrm{~h}$ to make it ready for microbial experiment.

To this end, strains under study, which were mentioned above, were used. Moreover, various concentrations of AgNPs were prepared. In each plate, 70 $\mu \mathrm{L}$ Muelller-Hinton Broth culture medium was prepared and $70 \mu \mathrm{l}$ of papared nanoparticles of by extract were added to 96-well microtiter plates. Then, $70 \mu \mathrm{L}$ of bacterial suspension equal to $0.5 \mathrm{McFarland}$ was added to each plate. As a whole, this experiment was carried out using $210 \mu \mathrm{L}$ volume in each well. The first plate was considered as positive control plate (bacterium and culture 
medium) and the last plate was considered as negative control plate (AgNPs and bacterium). Samples were maintained in incubator for $24 \mathrm{~h}$ at $37^{\circ} \mathrm{C}$. The first well was reported as the least inhibitory concentration in microliter/mL without turbidity.

\section{Results and discussion}

Effect of $\mathrm{pH}$ on silver nanoparticle synthesis

The extreme effect of $\mathrm{pH}$ on the process of AgNPs formation has been reported. As explained earlier, the present study explored the effect of $\mathrm{pH}$ on AgNPs synthesis using Fumaria officinalis extract at different $\mathrm{pH}$ regions (2-10). Figure 3 shows the results of UV-Vis analysis of the synthesized AgNPs with different $\mathrm{pH}$ amounts. A change in the color of the solution from pale yellow to dark brown is observed. The analysis of absorbance points regarding the solution with $\mathrm{pH}=10$ revealed the largest absorbance at wavelength $419 \mathrm{~nm}$, confirming the presence of AgNPs. A common trend is that the SPR (surface plasmon resonance) peak shifts toward the longer wavelength region also becomes narrower when the $\mathrm{pH}$ value increases. Extreme variances of absorbance for the solutions with different $\mathrm{pH}$ amounts indicated that the size of obtained nanoparticles is to larger extent dependent on $\mathrm{pH}$ because of the direct relationship between absorbance wavelength and nanoparticles' size. At $\mathrm{pH}=2$ and 4 , no considerable change is observed, indicating that no synthesis is occurred. However, as the solution $\mathrm{pH}$ increased to 6,8 and 10, absorbance increased remarkably, confirming an increase in the synthesized nanoparticles at that region [32].

Assuming that the change in the SPR peak shows a change in the size of AgNPs and therefore any shift of the peak toward the longer wavelength is accompanied by an increase in the size of the formed AgNPs, then raising the $\mathrm{pH}$ of the solution results in the formation of nanoparticles with larger size. The extreme changes observed in the UV-Vis images regarding the solutions with different $\mathrm{pH}$ amounts revealed that size and morphology of the obtained nanoparticles are to large extent dependent on $\mathrm{pH}$. Therefore, $\mathrm{pH}=10$ was determined as optimal due to its greatest absorbance as well as totally symmetric peak.

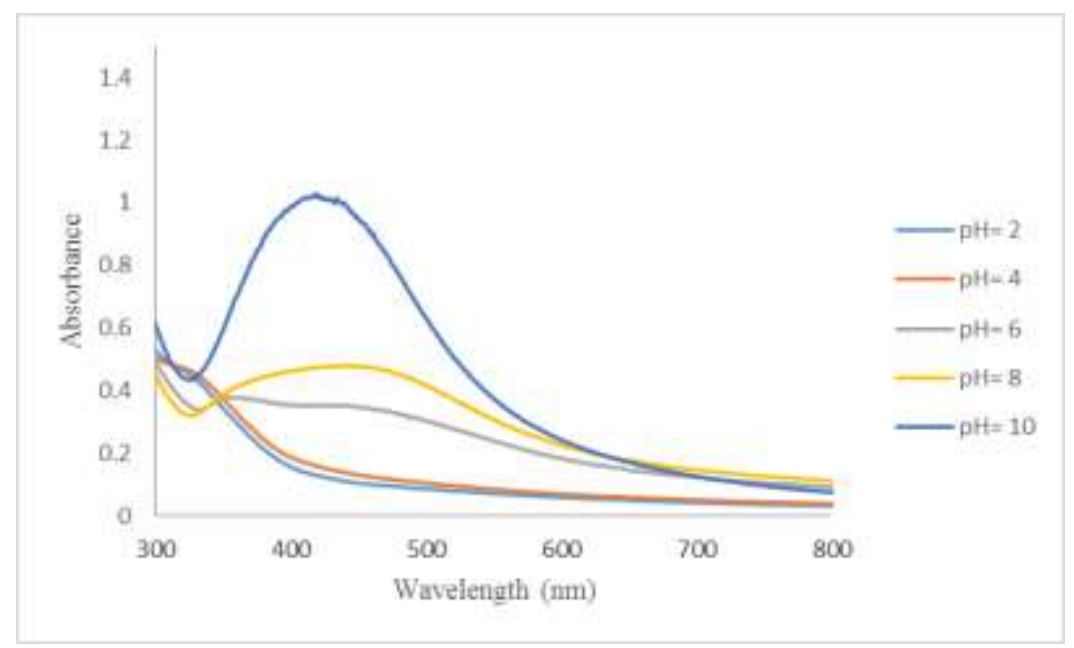

Figure 3. Effect of $\mathrm{pH}$ on AgNPs synthesis by fumaria officinalis extract

Effect of extract volume on silver nanoparticle synthesis
Plants act as reduction and stabilizing agents in green synthesis of nanoparticles [33]. Fumaria officinalis is 
full of natural compounds including antioxidants, alkaloids, and flavonoids which play role in metal ions reduction, changing them into metal atoms at nanometric scales and synthesized nanoparticles stabilizing. According to Figure 4, as the extract volume increases from 2 to $8 \mathrm{~mL}$, an increase in absorbance of AgNPs is observed. The increase of extract volume leads to the increase of secondary compounds available in the solution, thus resulting in more synthesized nanoparticles with smaller sizes following the increase of absorbance [34]. Lower amounts of extract volume resulted in less nanoparticles with larger sizes (due to the peak width). The upmost results show notable similarity with the obtained results of the experiences conducted with Cinnamomum zeylanicum and Cinnamomum camphora extracts. Therefore, the optimal volume was set 8 $\mathrm{mL}$. The above results show remarkable similarity with the results of the experiments conducted with bark extract of Cinnamomum zeylanicum and with the leaves of Cinnamomum camphora [35,36]. Moreover, it is reported in Pinus eldarica bark extract that, the particle size of Ag nanoparticles decreases with an increase in the extract quantity [34].

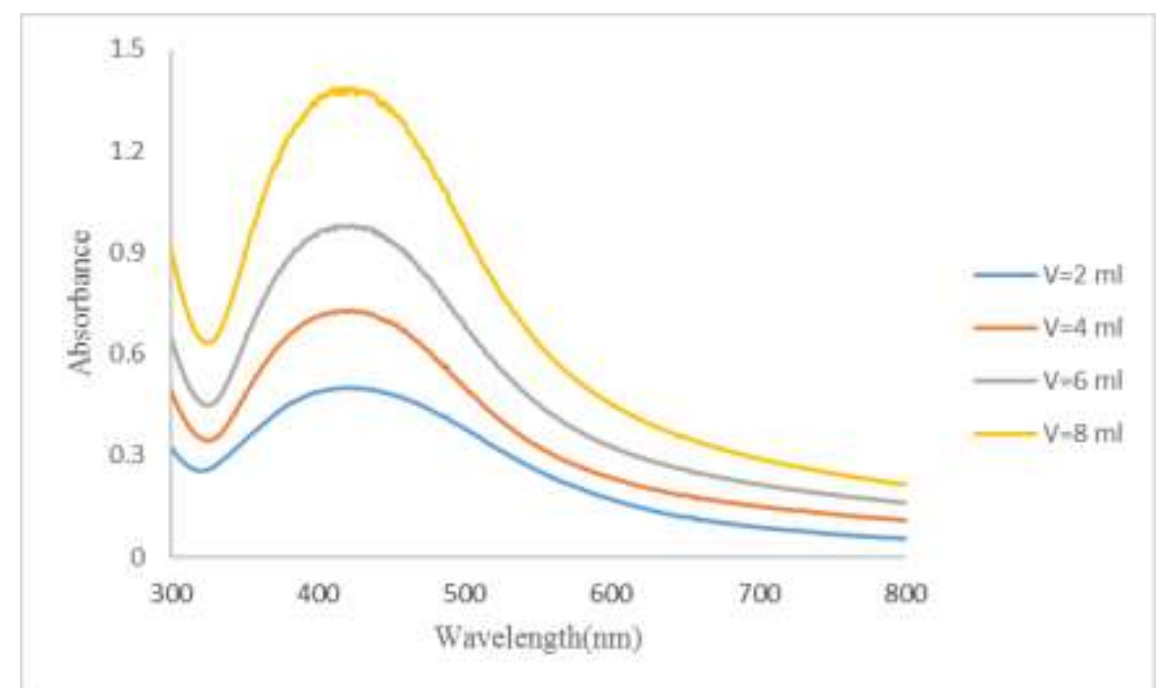

Figure 4. Effect of Fumaria officinalis extract solution on AgNPs synthesis

Effect of metal salt concentration on silver nanoparticle synthesis

To obtain an optimal concentration for $\mathrm{AgNO}_{3}$ solution, solutions with concentrations ranging from 1 to $10 \mathrm{mM}$ were constructed, and $8 \mathrm{~mL}$ of the extract was added to them. Then, $\mathrm{pH}=10$ determined for them. Finally, the solutions were submitted to a UV-Vis analysis at regions 330-800 $\mathrm{nm}$ (Figure 5). Studies have shown that as the amount of metal ions increases, more ions are reduced, thus leading to the formation of more nanoparticles. According to Figure 5, with gradually increasing the amount of Ag+ concentration, absorbance of AgNPs increased remarkably as well. The absorbance peak broadens with increase in $\mathrm{AgNO}_{3}$ concentration denoting synthesis of large sized Ag nanoparticles. This could be due to very Ag+ adsorbed upon the surface of preformed nucleus, wherein the secondary reduction action takes place leading to foundation of larger Ag nanoparticles. [37] . As a result, $10 \mathrm{mM}$ was selected as the optimal concentration for $\mathrm{AgNO}_{3}$ solution. 


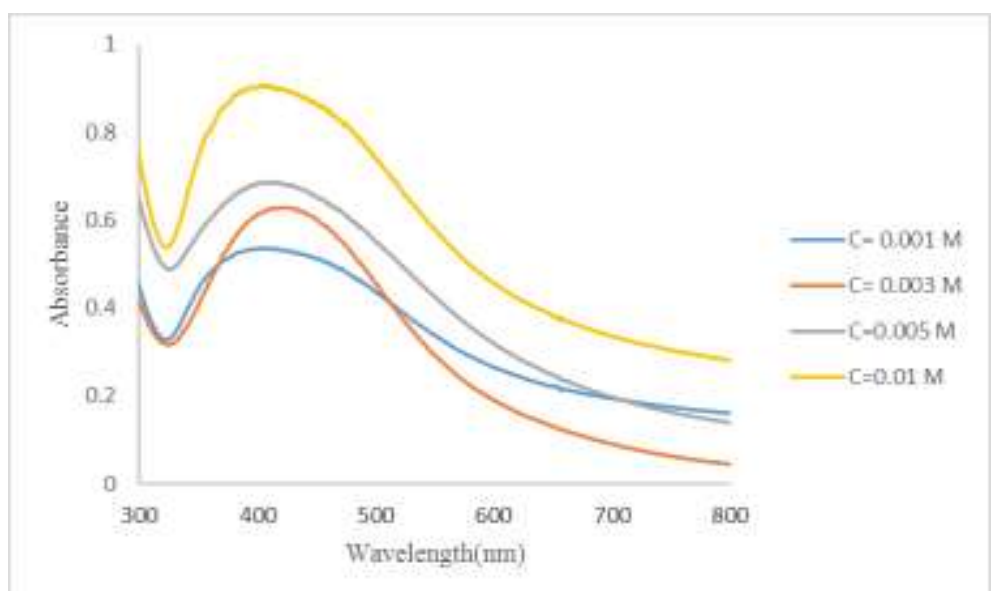

Figure 5. Effect of nitrate solution concentration on AgNPs synthesis by Fumaria officinalis extract

Effect of temperature on silver observed that Ag nanoparticles nanoparticle synthesis

This study accomplished the synthesis of AgNPs through Fumaria officinalis extract at room temperature. To obtain an optimal temperature and reach more desired nanoparticles, solutions resulted from the mixture of extract with silver salt were exposed to $25,45,65,80$, and $100{ }^{\circ} \mathrm{C}$, following a UV-Vis analysis (Figure 6). The results showed that an increase in temperature led to a considerable increase in absorbance arising from Surface Plasmon Resonance analysis. In a similar study, Cruz et al. biosynthesized using lemon verbena (Lippia citriodora) extracts, with increase in reaction temperature, the formation of the $\mathrm{Ag}$ nanoparticle reduction is increased [38]. In another experiment, Khalil et al. reports that the gradually rate of Ag NP synthesis by olive leaf extract at room temperature can be advanced by increasing reaction temperature of mixture [39]. Alike results got with Fumaria officinalis extract in our study, therefore, the optimal temperature $100{ }^{\circ} \mathrm{C}$ was selected.

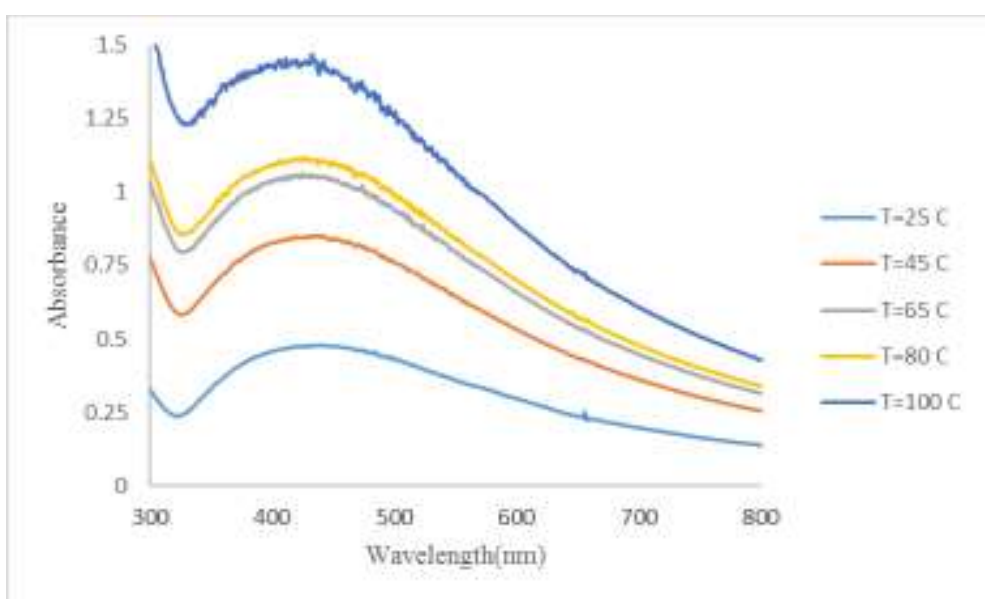

Figure 6. Effect of temperature on AgNPs synthesis by Fumaria officinalis extract

Effect of time on silver nanoparticle synthesis

As other mentioned parameters, time has an effective role in the synthesis and stabilization of nanoparticles. The results of this study showed as interaction time increased from the moment of mixing until $2 \mathrm{~h}$ after that, absorbance amount increased remarkably (Figure 7). From 80 to $100 \mathrm{~min}$, not only absorbance was observed but a decrease was observed due to the sticking of particles with 
smaller sizes to each other and forming nanoparticles with larger sizes. However, an increase was also observed at 120 min, indicating larger amounts of synthesized nanoparticles. As it is observed, at all times, absorbance peaks were similar and wide, with only the difference in the absorbance amount and increased height as the time passed. The peaks' width reveals the large size of nanoparticles. Therefore, it can be concluded that the time parameter has just increased the number of particles and has had not any effect on the shape or size of nanoparticles. As a result, 120 min was set as the optimal time. The data agrees with the obtained results of the experiments perform with olive leaf extract [39].

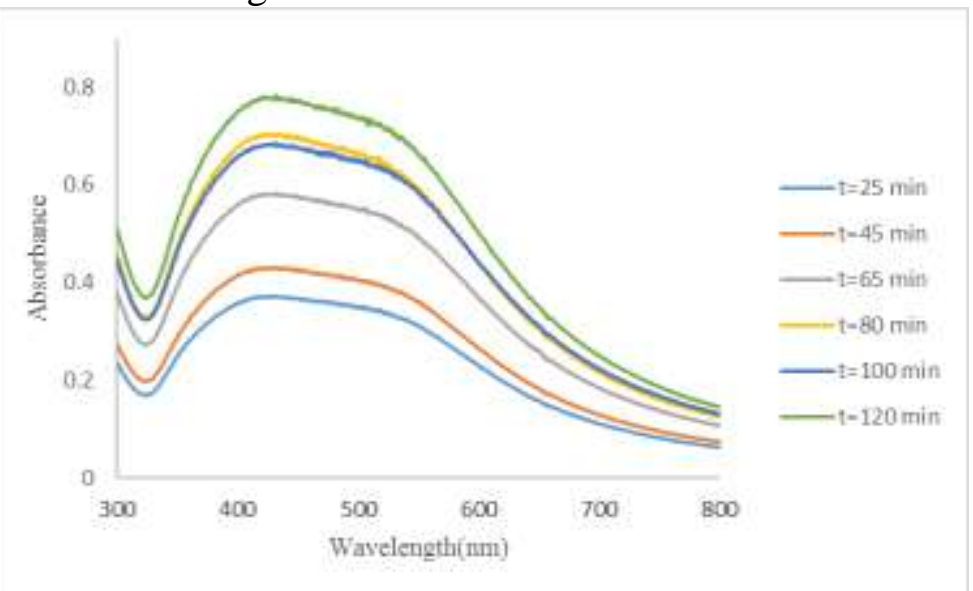

Figure 7. Effect of time on AgNPs synthesis by Fumaria officinalis extract

Characterization of synthesized AgNPs using Fumaria officinalis

$U V$-Vis Spectrophotometry analysis

The first sign confirming the formation of AgNPs was a change in the solution's color to dark brown followed by the formation of colloidal solution. As suggested earlier, the nanoparticles were synthesized at optimal conditions and characterized by various techniques such as UV-Vis spectrophotometry. The results are presented in Figures 3-7. As it is observed, the extract mixed with silver revealed peaks at regions $400-450 \mathrm{~nm}$ may be due to the excitation of surface plasmon resonance (SPR) effect of silver nanoparticles, while such peak is not observed in the case of pure solution. The leaf extract of Fumaria officinalis displayed optical property, as it clearly absorbed in the UV/Visible region (322 $\mathrm{nm}$ ) with intensity of 0.58 a.u. (Figure 8 ). This also showed the water soluble orgnic compounds (the phytochemicals) in the extract that it may act as reducing to reduce $\mathrm{Ag}+$ to $\mathrm{Ag0}$. This result is one of the simplest indicators of AgNPs synthesis, which is in agreement with previous reports [18, 21, 40, and 41]. Silver is found to have the highest conductivity and stronger peak as compared to other noble metals because of the cumulative fluctuations of free electrons on the metal surface induced by the electromagnetic field.

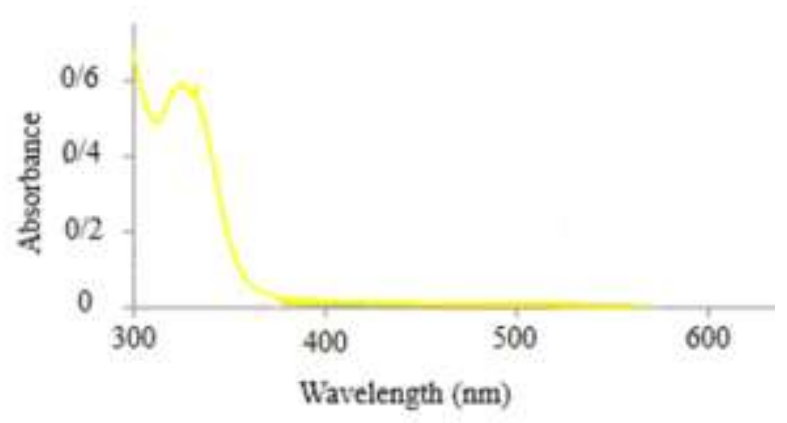

Figure 8. UV-Vis spectra of Fumaria officinalis extract

The results of $X$-Ray diffraction analysis XRD analysis of the synthesized AgNPs crystallite structure is shown in Figure 9. 
AgNPs formed at regions with $2 \theta$ values of 38.1396, 44.3508, 64.5129, and 77.4606 revealed sharp peaks, confirming successful synthesis of AgNPs [42]. Structural analysis indicated that nanoparticles had crystallite structure with Miller indices (1 111$),\left(\begin{array}{lll}2 & 0 & 0\end{array}\right),\left(\begin{array}{lll}2 & 2 & 0\end{array}\right)$, and $\left(\begin{array}{lll}3 & 1 & 1\end{array}\right)$ at cubic face-centered (related to FCC structure of AgNPs), being in complete agreement with standard pattern of Ag87-0117 XRD. Sharp peaks observed that patterns are indicative of high degree of nanoparticles' crystallite state. Peak 111 is higher and sharper than other peaks, confirming that nanoparticles' crystallite structure is more observed at this region. The average size of synthesized crystallite particles measured by Debye-Scherrer formula (Equation 1) is found to be $\sim 25 \mathrm{~nm}$ (Table 1).

$\mathrm{D}=0.89 \lambda / \beta \operatorname{Cos} \theta$

Where X-ray wavelength $(\lambda)$ is $1.5406, \beta$ indicates FWHM (full width at half maximum) and $\theta$ denotes the diffraction angle.

It is clear that for the synthesized silver nanoparticles, the (llll 111 lattice plane is the preferred orientation, which is also known for their high antibacterial activity [43].

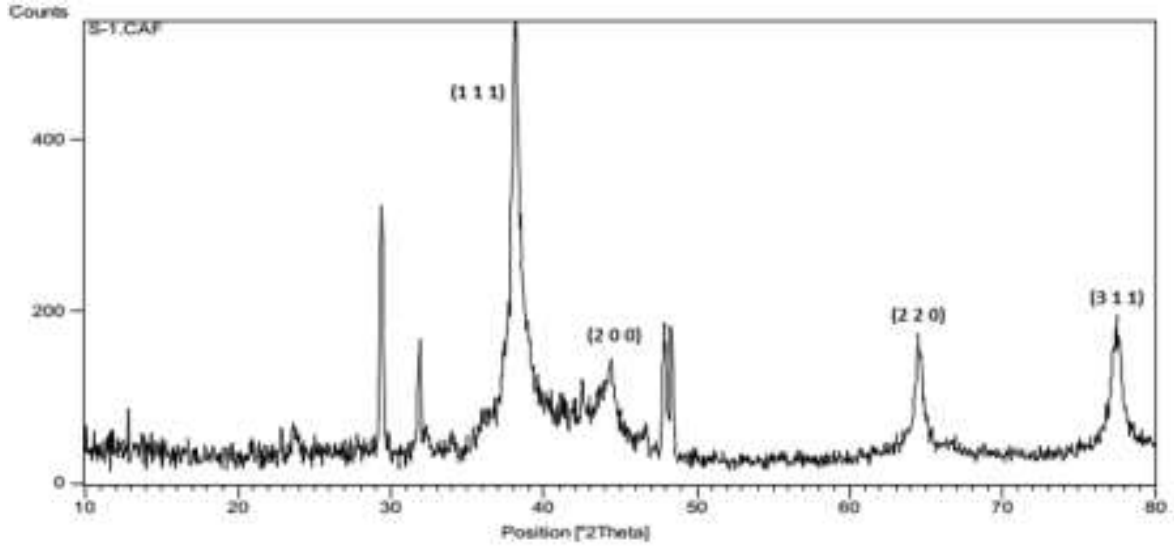

Figure 9. X-ray diffractograms of AgNPs synthesized using by Fumaria officinalis extract.

Table 1. X-ray diffraction data for AgNPs

\begin{tabular}{lccccc} 
No. & $\begin{array}{c}\text { Position } \\
{\left[{ }^{\circ} \text { 2Theta }\right]}\end{array}$ & $\begin{array}{c}\text { FWHM } \\
{\left[{ }^{\circ} 2 \text { Theta }\right]}\end{array}$ & h k 1 & $\begin{array}{c}\text { d-spacing } \\
\left({ }^{\circ} \mathrm{A}\right)\end{array}$ & size $(\mathrm{nm})$ \\
$\mathbf{1}$ & 38.1396 & 0.29526 & 111 & 2.35888 & 28.94 \\
$\mathbf{2}$ & 64.5129 & 0.39361 & 220 & 1.44451 & 24.26 \\
$\mathbf{3}$ & 77.4606 & 0.4800 & 311 & 1.23188 & 21.57 \\
& & & & & Ave. $=24.92$ \\
\hline
\end{tabular}

\section{FESEM, TEM and EDX analysis}

Figures 10 and 11 indicate output of FESEM and TEM analysis. The morphology of AgNPs was studied by FESEM analysis. The image showed that the synthesized AgNPs were predominantly disperse spherical in shape with no agglomeration. According to the Figure 11, AgNPs seem darker, with a spherical shape and appropriate distribution. The bright ground observed around AgNPs is related to the solution. The solution density against light transmission is less than AgNPs density. That is why AgNPs are shown darker and the solution seems brighter in the image. The synthesized nanoparticles are 5-40 $\mathrm{nm}$ in diameter. This result has complete 
conformity to the results of XRD of the experiments conducted with analysis. This data agrees with the results Chenopodium leaf extract [37].

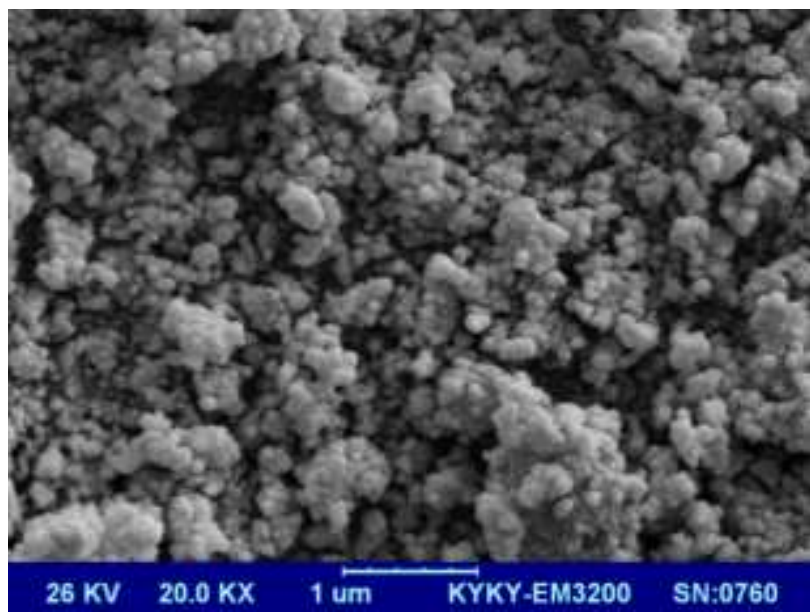

Figure 10. FESEM image of AgNPs synthesized using Fumaria officinalis extract

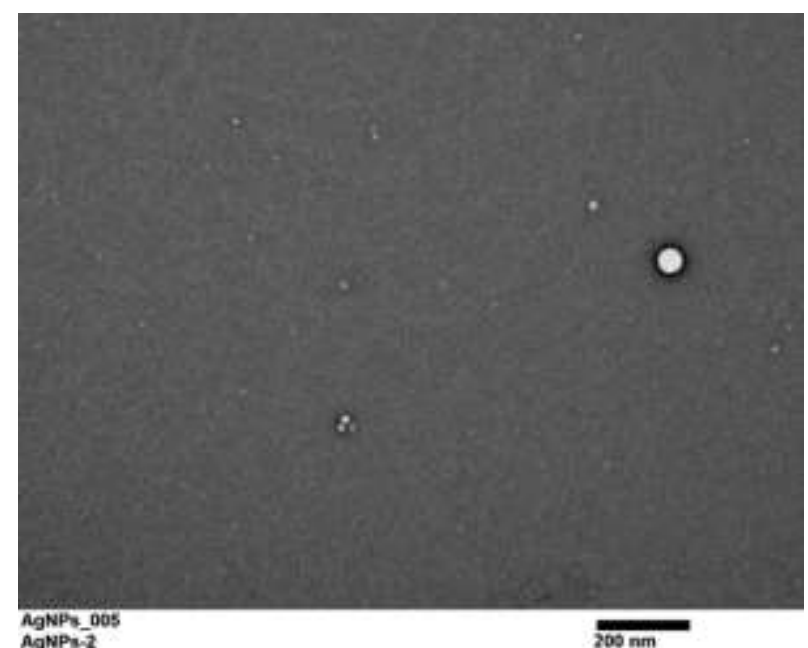

Figure 11. TEM image of AgNPs synthesized at the optimized condition

The elemental analysis of chemical constituents were determined by EDX. The EDX results of this analysis are given in Figure 12; samples show strong signals corresponding to elemental silver at $3 \mathrm{keV}$, and show a large amount of silver (61.1 atomic \%.), carbon (19.87 atomic \%), oxygen (6.81 atomic \%) and nitrogen $(2.45$ atomic \%) which could have arisen from the leaf extract.

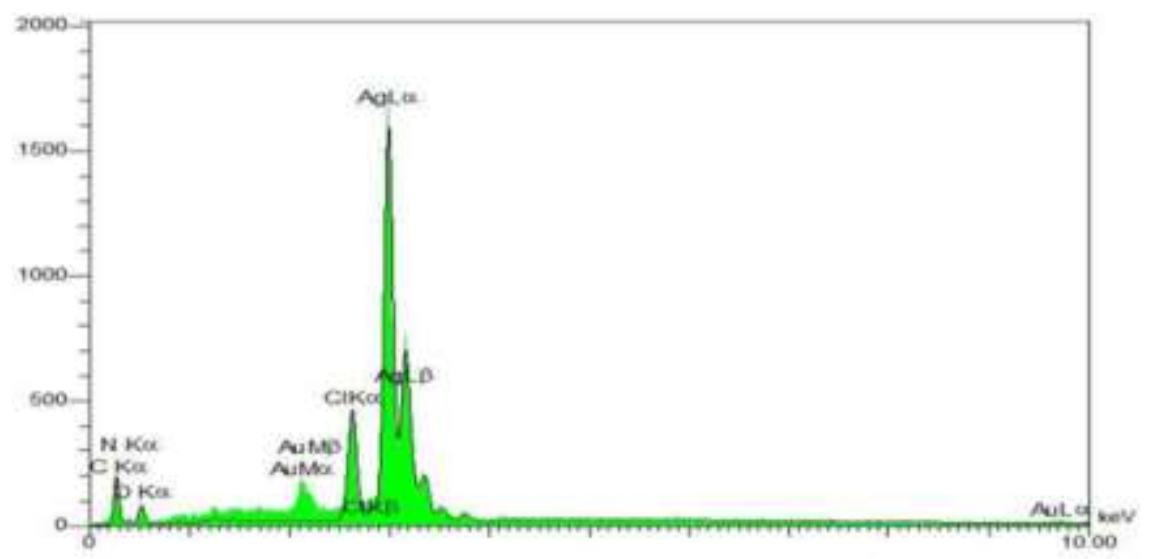

Figure 12. EDX spectra of AgNPs synthesized at the optimized condition 
FTIR analysis

The FTIR analysis of the synthesized Ag NPs and Fumaria officinalis extract is illustrated in Figure 13 a, b. The presence of the bands in both spectra regions of $\sim 3400,2920,1619,1384, \sim 1080$ and 800-600 $\mathrm{cm}^{-1}$, corresponds to the hydroxyl functional group (phenolic and alcohols compounds) or from $-\mathrm{NH}$ vibrations (proteins, amides and amines), (C-H aliphatic stretching)[19], $(\mathrm{NH}) \mathrm{C}=\mathrm{O}(($ Amid I and (Amid II), $\mathrm{CH}$ or $\mathrm{OH}$ vibrations (alcoholic types of polysaccharides), (C-O, C-O-C and C-N vibrations), and $\mathrm{R}-\mathrm{CH}$ groups, respectively [44], which are responsible for the reduction of $\mathrm{Ag}^{+}$into $\mathrm{Ag}^{0}$.

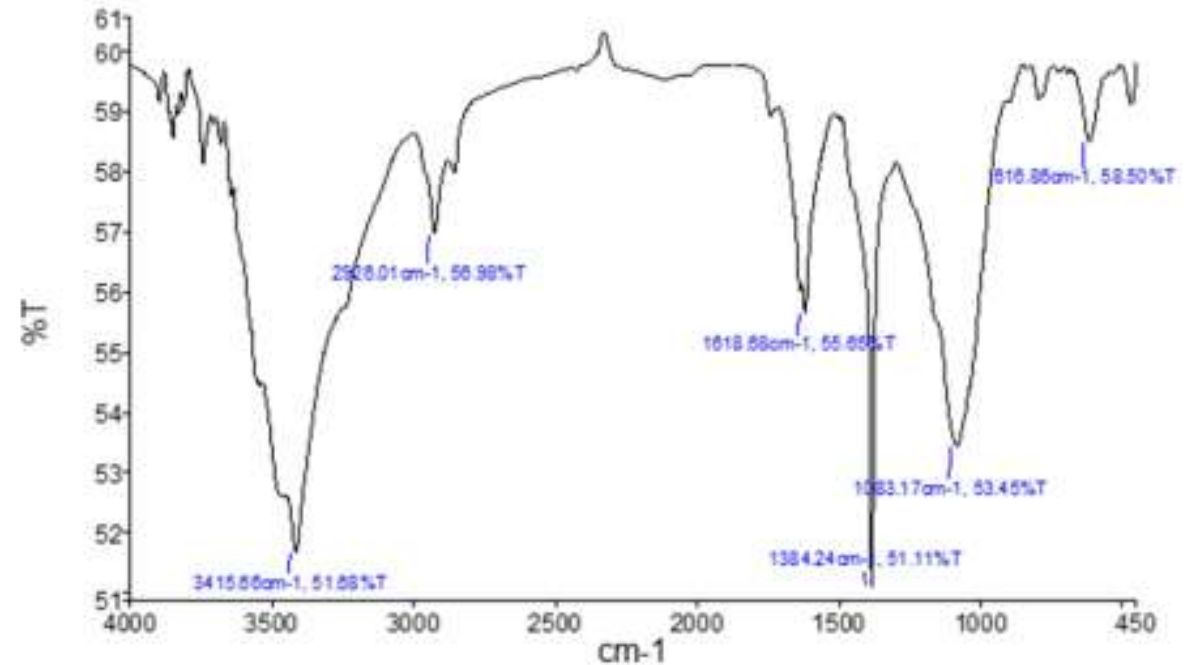

a)

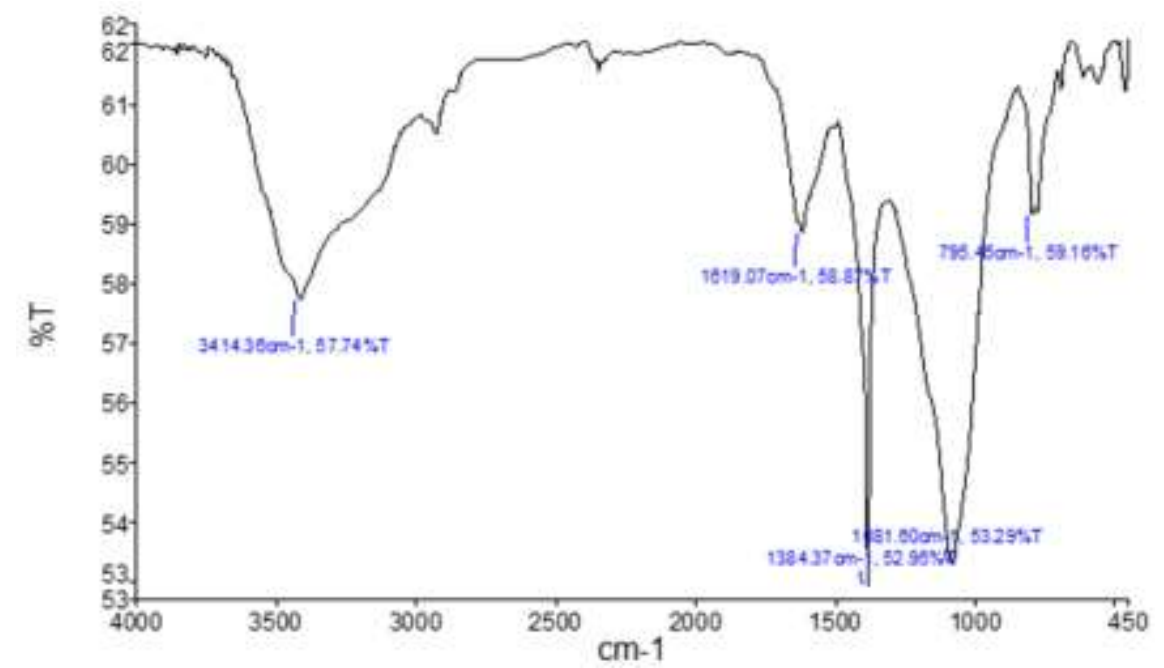

b)

Figure 13. FTIR analysis of a) synthesized Ag NPs and, b) Fumaria officinalis extract

\section{Antibacterial test}

The results of antibacterial tests of AgNPs, extract, and silver nitrate by the agar disc diffusion method and minimum inhibitory concentration (MIC) determination are shown in Tables 2 and 3. The antibacterial effects of AgNPs have been shown to have a significant impact on two tested strains, which is also increased by increasing the concentration of AgNPs. For extract, $\mathrm{AgNO}_{3}$ and AgNPs, the inhibition zone diameter of Escherichia coli and Staphylococcus aureus were measured as 5, 13, $22 \mathrm{~mm}$ and 6, 14, $20 \mathrm{~mm}$ (Figure 14), respectively. The diameter of 
growth inhibition zone was larger in Escherichia coli than Staphylococcus aureus due to the difference between the membrane structure and composition of gram-negative and positive bacteria. This implies that the AgNPs synthesized using extract of Fumaria officinalis have promising antibacterial potential against strains of bacteria. The minimum inhibitory concentration on Escherichia coli and Staphylococcus aureus for AgNPs with a mean diameter of $24 \mathrm{~nm}$ was 12.5 and $6.25 \mu \mathrm{g} / \mathrm{mL}$, respectively; however, with increasing concentrations (above $12.5 \mu \mathrm{g} / \mu \mathrm{L}$ ), growth in both strains was inhibited. Results obtained in our approach is in good agreement with other researcher's findings. In the study of Vonwhite et al. and Iravani et al., the AgNPs synthesized from Garlic and Pinus eldarica with sizes of 10-40 and 20-30nm showed good antibacterial properties against some bacteria $[34,45]$. Antibacterial activity of AgNPs on a gram-positive and gram-negative bacteria chain has not identical form, but one has to follow the other. There are conflicting reports of antibacterial activity against gram positive and gram negative bacteria. Some researchers have pointed out that gram-negative bacteria are more sensitive to AgNPs than grampositive bacteria [46], while converse results are also mentioned by other researchers. Different sensitivities of the species of both reported bacteria can be attributed to different structural properties of the species [47] such as the shape and size of AgNPs, the amount of bacteria inoculated, the time of presentation, and the nutrient medium used during the antibacterial activity analysis. In recent times, the researchers have produced 10 to $70 \mathrm{~nm}$ size, spherical shaped AgNPs from Beetroot, Emblica officinalis and Vitis vinifera fruit extract shows excellent antimicrobial activity against $S$. aureus, B. subtilis, E. coli, and K. Pneumoniae $[48,49]$. Veerasamy et al. investigated the effect of nanoparticles prepared by Mangosteen leaf against Staphylococcus aureus and Escherichia coli and observed that the zones of growth inhibition of Escherichia coli and Staphylococcus aureus were $15 \mathrm{~mm}$ and $20 \mathrm{~mm}$ in diameter, respectively [50]. This result was in accordance with the results of the present study.

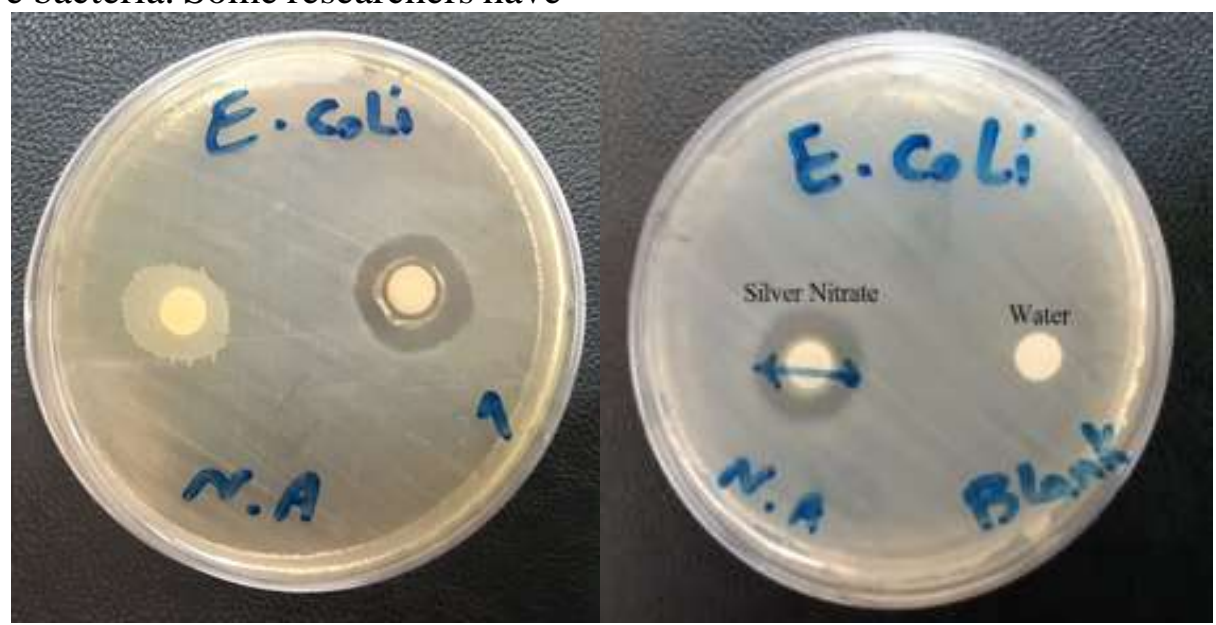

A) 


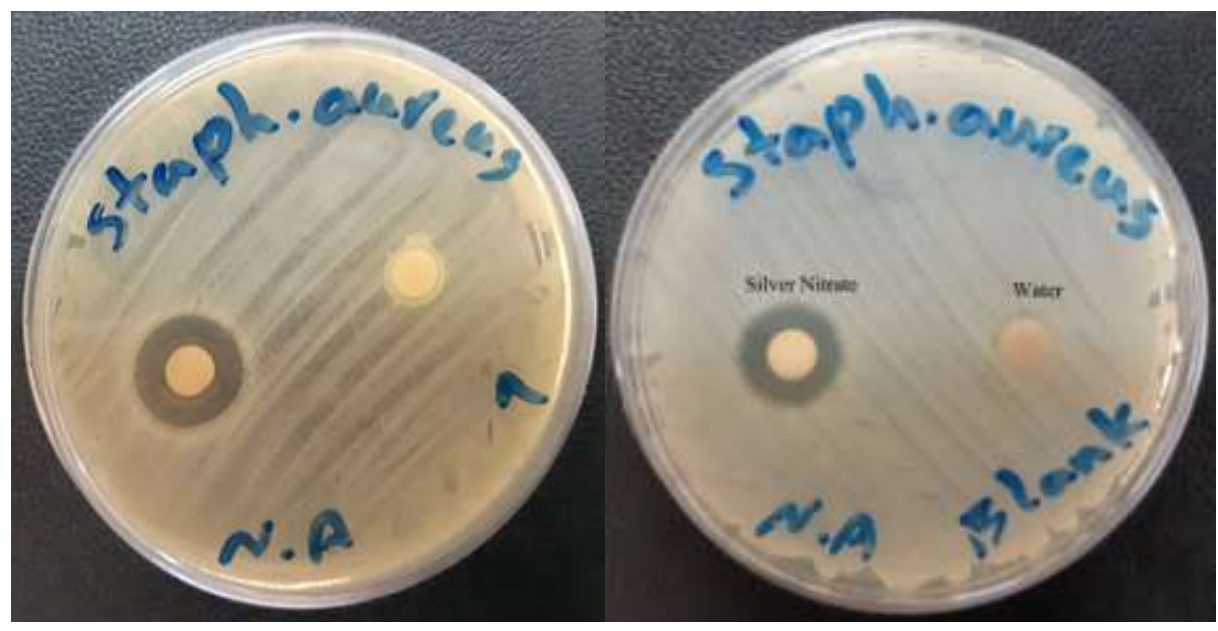

B)

Figure 14. Zone of inhibition against: A) Escherichia coli, B) Staphylococcus aureus

Table 2. Comparison of Antimicrobial activity of samplesand zone of inhibition

\begin{tabular}{ccccccccc}
\hline $\begin{array}{c}\text { Experimental } \\
\text { solution }\end{array}$ & \multicolumn{3}{c}{$\begin{array}{c}\text { Zone of inhibition }(\mathrm{mm}) \\
\text { Escherichia coli }\end{array}$} & \multicolumn{3}{c}{$\begin{array}{c}\text { Zone of inhibition }(\mathrm{mm}) \\
\text { Staphylococcus aureus }\end{array}$} \\
\hline Extract & 5 & 5 & 5 & 5 & 6 & 6 & 6 & 6 \\
$\mathrm{AgNPs}$ & 22 & 21.5 & 22 & 21.83 & 20 & 20 & 19 & 19.66 \\
$\mathrm{AgNO}_{3}$ & 13 & 13 & 13 & 13 & 14 & 14 & 14 & 14 \\
\hline
\end{tabular}

Table 3. Minimum inhibitory concentration (MIC) of AgNPs against standard strains of two bacteria

\begin{tabular}{c|ccccccccccc}
\hline \multirow{2}{*}{ Strain } & \multicolumn{10}{c}{ AgNPs concentration $(\mu \mathrm{g} / \mu \mathrm{L})$} \\
\cline { 2 - 11 } & 0.39 & 0.78 & 1.56 & 3.12 & 6.25 & 12.5 & 25 & 50 & 100 & 200 \\
\hline Escherichia coli & + & + & + & + & + & + & - & - & - & - \\
$\begin{array}{c}\text { Staphylococcus } \\
\text { aureus }\end{array}$ & + & + & + & + & + & - & - & - & - & - \\
\hline
\end{tabular}

\section{Conclusion}

In the present study, an eco-friendly, non-toxic, cost-effective method for synthesis of AgNPs from fumaria officinalis extract as reducing agent was reported. The formation of AgNPs was analyzed by UV-Vis spectrophotometer at room temperature. The SPR band appeared at regions 400-450 $\mathrm{nm}$. Spherical shaped, polydispersed nanoparticles with $25 \mathrm{~nm}$ size are produced and confirmed by XRD, FESEM, TEM and EDX. FTIR analysis suggests that the biomolecules containing functional groups with nitrogen or oxygen such as $(\mathrm{NH}) \mathrm{C}=\mathrm{O}$, $\mathrm{NH}, \mathrm{C}-\mathrm{O}-\mathrm{C} \mathrm{C}=\mathrm{O}$, and $\mathrm{OH}$ group play the main role in the $\mathrm{Ag}+$ reduction. Prepared AgNPs showed high antimicrobial activity against both
Gram-positive (Staphylococcus aureus) and Gram-negative bacteria (Escherichia coli). The diameter of growth inhibition zone was larger in Escherichia coli than Staphylococcus aureus due to the difference between the membrane structure and composition of gramnegative and positive bacteria. Generally, it could be said that biosynthesis of AgNPs using plants extracts is a green, cost-effective, and safe method because no toxic material is applied and no side effects are observed. In addition, plants extracts have vigorous antimicrobial properties which can replace antibiotics.

\section{Acknowledgments}

The authors gratefully acknowledge Islamic Azad University of Arak for financial support of this research. 


\section{References}

[1] S. Rajeshkumar, C. Malarkodi, M. Vanaja, G. Gnanajobitha, K. Paulkumar, M. Vanaja, C. Kannan and G. Annadurai, Journal of Nanostructure in Chemistry., 2013, 3, 44.

[2] H. Saeidian, H. Sadighian, M. Arabgari, Z. Mirjafary, S.E. Ayati, E. Najafi, F. Matloubi, Moghaddam. Res. Chem. Intermediat., 2018, 44, 601-612.

[3] Z. Arzehgar, A. Aydi, M. Mirzaei Heydari, Asian J. Green Chem., 2018, 2, 281-298.

[4] N. Rasouli, M. Movahedi, E. Aghabeikzadeh Naeini, Iran. Chem. Commun., 2018, 6, 169-179.

[5] M. Diyanat, H. Saeidian, S. Baziar, Z. Mirjafary, Environ. Sci. Pollut. R., 2019, 26, 21579-21588.

[6] Z. Mirjafary, H. Saeidian, A. Sadeghi, F. Matloubi Moghaddam, Catal. Commun., 2008, 9, 299-306.

[7] H. Saeidian, S. Vahdati Khajeh, Z. Mirjafary, B. Eftekhari-Sis, RSC Advances., 2018, 8, 38801-38807.

[8] P. Rauwel, S. Küünal, F. Ferdov, E. Rauwel, Advances in Materials Science and Engineering., 2015, Article ID 682749.

[9] T. AB Matina, N. Ghasemia, K. Ghodratib, M. Ramezani, Iran. Chem. Commun., 2019, 7, 594-606.

[10] F. Matloubi Moghaddam, M. Doulab, H. Saeidian, Scientia Iranica., 2012, 19, 1597-1600.

[11] F. Matloubi Moghaddam, H. Saeidian, Mater. Sci. Eng: B., 2007, 139, 265-269.

[12] A. Husen, K.S. Siddiqi, Phytosynthesis of nanoparticles: concept, controversy and application, Nano. Res. Lett., 2014, 9, 229.

[13] K.S. Siddiqi, A. Husen, J. Trace Elements Med. Biol., 2017, 40, 10-23.

[14] S. Azizi, M.B. Ahmad, F. Namvar, R. Mohamad, Materials Letters., 2014, 116, 275-277.
[15] H. Khanehzaei, M.B. Ahmad, K. Shameli, Z. Ajdari, International Journal of Electrochemical Science., 2014, 9, 8189-8198.

[16] G. Rajakumar, T. Gomathi, M. Thiruvengadam, V.D. Rajeswari, V.N. Kalpana, I.M. Chung, Micro. Pathol, 2017, 103, 123-8.

[17] Aramwit, N. Bang, J. Ratanavaraporn, J.S. Ekgasit, Nano. Res. Lett., 2014, 9,79.

[18] M. Parlinska-Wojtan, M. KusLiskiewicz, J. Depciuch, O. Sadik, Bioprocess Biosyst. Eng., 2016, 39, 1213-23.

[19] M. Ahamed, M.S. AlSaalhi, M.K.J. Siddiqui, Clin. Chim. Acta., 2010, 411, 1841-8.

[20] J.H. Crabtree, R.J. Burchette, R.A. Siddiqi, I.T. Huen, L.L. Handott, A. Fishman, Perit. Dial. Int., 2003, 23, 36874.

[21] I. Fatimah, J. Adv. Res., 2016, 7, 961-9.

[22] G.S. Karatoprak, G. Aydin, B. Altinsoy, C. Altinkaynak, M. Kos, I. Ocsoy, Enzy. Micro. Technol., 2017, 97, 21-6.

[23] M. Parveen, F. Ahmad, A.M. Malla, S. Azaza, Appl. Nanosci., 2016, 6, 26776.

[24] M. Dhayalan, M.I.J. Denison, A.L. Jegadeeshwari, K. Krishnan, N.N. Gandhi, Nat. Prod. Res., 2017, 31, 4658.

[25] P. Velmurugan, K. Anbalagan, M. Manosathyadevan, K.J. Lee, M. Cho, S.M. Lee, J.H. Park, S.J. Oh, K.S. Bang, B.T. Oh, Bioprocess Biosyst. Eng., 2014, 37, 1935-1943.

[26] N. Abdel Raouf, N.M. Al-Enazi, I.B.M. Ibraheem, Arabian J. Chem., 2017, 10, S3029-S3039.

[27] N. Durán, D. Priscyla, P.D. Marcato, O. Alves, G. De Souza, E. Esposito, J. Nanobiotechnol., 2005, 3, 17. 
[28] N.G. Bisset M. Wicht, 2nd ed. CRC Press. London. 2001, 214-6.

[29] J. Soušek, D. Guédon, T. Adam, H. Bochořáková, E. Táborská, I. Válka, V. Šimáneket, Phytochemical Analysis., 1999, 10, 6-11.

[30] M.H. Rousta, N. Ghasemi, Rev. Roum. Chim., 2019, Accepted.

[31] H. Veisi, M. Kavian, M. Hekmati, S. Hemmati, Polyhedron., 2019, 161, 338345.

[32] M.K. Alqadi1, O.A. Abo Noqtah, F.Y. Alzoubi, J. Alzouby, K. Aljarrah, Materials Science-Poland., 2014, 32, 107-111.

[33] S. Iravani, Green Chem., 2011, 13, 2638- 2650.

[34] S. Iravani, B. Zolfaghari, Bio.Med. Research International., 2013, Article ID 639725.

[35] M. Satishkumar, K. Sneha, S.W. Won, C.W. Cho, S. Kim, and Y.S. Yun, Colloids Surf. B: Biointerface., 2009, 73, 332-338.

[36] J. Huang, Q. Li, D. Sun, Y. Lu, Y. Su, X. Yang, H. Wang, Y. Wang, W. Shao, N. He, J. Hong, and C. Chen, Nanotechnology., 2007, 18, 105104105114.

[37] A.D. Dwivedi, G. Krishna, Colloids and Surfaces A: Physicochem. Eng. Aspects., 2010, 369, 27-33.

[38] D. Cruz, L.F. Pedro, M. Ana, D.V. Pedro, M.L. Serralheiro, R. Ana L. Lino, Colloids and Surfaces B: Biointerfaces., 2010, 81, 67-73.

[39] M.M.H..Khalil, E.H.Ismail, K.Z. El-Baghdady, M. Doaa, Arabian J. Chem., 2014, 7, 1131-1139.
[40] S. Kaviya, J. Santhanalakshmi, B. Viswanathan, Journal of Nanotechnology., 2011, 152970152974.

[41] F. Mohammadi, M. Yousefi, R. Ghahremanzadeh, Adv. J. Chem. A, 2019, 2, 266-275.

[42] S. Mehdizadeh, N. Ghasemi, M. Ramezani, Iran. Chem. Commun., 2019, 7, 655-668.

[43] N. HULKOTI, ph.D THESIS,, 2016, KARNATAK UNIVERSITY, DHARWAD

[44] S. Hemmati, A. Rashtiani, M.M. Zangeneh, P. Mohammadi, A. Zangeneh, H. Veisi, Polyhedron., 2019, 15, 8-14. [45] G. Vonwhite, P. Kerscher, R.D. Brown, J. Morella, W. Mcallister, D. Dean, J. Nanomate., 2012, 26, 1-12. [46]. V. Gopinath, D.Mubarakali, S. Priyadarshini, N.M. Priyadharsshini, N. Thajuddin, P. Velusamy, Colloids and Surfaces B: Biointerfaces., 2012, 96, 697.

[47] A.J. Kora, R.B. Sashidhar, J. Arunachalam, Carbohydrate Polymers., 2010, 82, 670-679.

[48] G. Gnanajobitha, K. Paulkumar, M. Vanaja, S. Rajeshkumar, C. Malarkodi, G. Annadurai, C. Kannan, J. Nanostruct. Chem., 2013, 3,1-6.

[49] P.S. Ramesh, T. Kokila, D. Geetha, Spectrochim. Acta A Mol. Biomol .Spectrosc., 2015, 142, 339-43.

[50] R. Veerasamy, T. Z. Xin, S. Gunasagaran, J. Saudi Chem. Soc., 2011, $15,113-120$.

How to cite this manuscript: Seyed Saeid Mohammadi, Nahid Ghasemi, Majid Ramezani. Bio-fabrication of silver nanoparticles using naturally available wild herbaceous plant and its antibacterial activity. Eurasian Chemical Communications, 2020, 2(1), 87-102. 